\title{
Attachment of Giardia lamblia trophozoites to a cultured human intestinal cell line
}

\author{
P H Katelaris, A Naeem, M J G Farthing
}

\begin{abstract}
Attachment of Giardia lamblia trophozoites to enterocytes is essential for colonisation of the small intestine and is considered a prerequisite for giardia induced enterocyte damage. The precise mechanisms involved are still being debated and some earlier work has been performed in models of uncertain biological relevance. In this study, co-incubation of giardia with enterocyte-like differentiated Caco-2 cells was used as a model to study the influence of physical and chemical factors on attachment. Giardia attachment was maximal between one and eight hours and stable over pH 7·2-8.2 but it was reduced by acidification. Attachment was dependent on temperature and was maximal at $37^{\circ}$ and virtually abolished at $4^{\circ} \mathrm{C}$. It was reduced compared with controls $(p<0.05)$ by EDTA $2.5 \mathrm{mM}$ (mean (SEM) $32(4) \%)$, colchicine $12 \cdot 5 \mu M(35$ (5) $\%$ ), mebendazole $10 \mu \mathrm{g} / \mathrm{ml}$ (30 (3) $\%$ ), and cytochalasin B $1 \mu \mathrm{g} / \mathrm{ml}$ (34 (3)\%). Giardia attachment was also diminished by preincubation with mannose $50 \mathrm{mM}$ or mannose-6-phosphate $35 \mathrm{mM}$ (21 (4); 17 (5)\%) or by preincubating Caco-2 cells with concanavalin A $100 \mu \mathrm{g} / \mathrm{ml}(19$ (2)\%). Enhanced binding was not evident after trypsinisation of trophozoites. Scanning electron microscopy showed that giardia seemed to attach to the Caco-2 monolayer predominantly by its ventral surface but dorsal orientation was also observed. No difference in attachment was observed between three different giardia isolates or a parent isolate and its clone. Attachment of giardia to Caco-2 cells is primarily by cytoskeletal mechanisms, inhibitable by interference with contractile filaments and microtubules, while attachment by mannose binding lectin also seems to mediate binding.

(Gut 1995; 37: 512-518)
\end{abstract}

Keywords: Giardia lamblia, attachment, Caco-2 cells, cytoskeleton, lectin.

Department of

Gastroenterology, St

Bartholomew's

Hospital, London

EC1A 7BE

P H Katelaris

A Naeem

M J G Farthing

Correspondence to: Dr Peter Katelaris, University of Sydney, Gastroenterology Unit, Concord Hospital, Concord 2139, Sydney, Australia.

Accepted for publication 24 February 1995 brush border of enterocytes, a process which seems to be essential for colonisation and a prerequisite for giardia induced enterocyte dysfunction and clinical disease. ${ }^{12}$ Giardia seem to attach by physical and chemical mechanisms, although the precise mode of this is still debated. Trophozoites have a ventral disc, which is considered a specific attachment organelle, made up of coiled microtubules containing tubulin, cross bridges, and unique structures called microribbons that are perpendicular to the microtubules and cross bridges. ${ }^{34}$ Contractile filaments in the rim of the ventral disc may mediate attachment. ${ }^{5}$ Another mechanism of attachment suggested is a model in which flagellar motion provides a hydrodynamic force sufficient for attachment via the disc. ${ }^{6}$ There is also evidence for lectin mediated receptor-ligand binding. ${ }^{78}$ Previous studies of attachment have used a variety of model systems including synthetic surfaces such as plastic and glass, non-human cells such as isolated rat enterocytes and cultured rat enterocyte cell lines, and human cells. ${ }^{8-12}$ These models differ in their biological appropriateness for attachment studies and the diversity of findings from them is probably a reflection of this and the different experimental protocols and rigor employed. In particular, there is no uniformity of findings regarding the importance of microtubules, contractile filaments, or giardia lectin in the attachment process.

The human colonic adenocarcinoma derived epithelial cell line, Caco- 2 undergoes spontaneous differentiation in culture so that it functionally and structurally resembles small bowel enterocytes. ${ }^{13}$ Cells develop apical brush border membranes ${ }^{1415}$ which express brush border enzymes including disaccharidases and alkaline phosphatase. ${ }^{1617}$ Disaccharidase activity increases with time and is used as a marker of cell differentiation. ${ }^{17}$ This cell line is thus useful and appropriate for studies of hostpathogen interactions. In this work differentiated Caco- 2 cells were used as a physiological model to study the attachment of human isolates of $G$ lamblia trophozoites under a variety of physicochemical conditions.

\section{Methods}

AXENIC CULTURE OF GIARDIA TROPHOZOITES Giardia trophozoites were routinely cultured in $15 \mathrm{ml}$ screw capped glass tubes at $37^{\circ} \mathrm{C}$ in modified TYI-S-33 medium ${ }^{18}$ but without bile or antibiotics. Unattached organisms were removed by decanting the culture medium, and only wall adherent trophozoites were harvested for use in co-culture experiments. The human isolate WB (originally axenised from a traveller to Afghanistan with chronic diarrhoea) was used in most experiments. Comparative studies were performed with isolates RW6 and VNB3, both previously axenised from patients with chronic diarrhoea and WB clone 2 , obtained 
from the parent WB isolate by the technique of limiting dilution. ${ }^{19}$

\section{CACO-2 CELL CULTURE}

Caco- 2 cells (passage 88 ) were kindly provided by Dr I Hassan, Ciba-Geigy Pharmaceuticals, Horsham, UK. Cells were cultured at $37^{\circ} \mathrm{C}$ in $75 \mathrm{~cm}^{2}$ flasks in Dulbecco's modified Eagle's medium, supplemented by $10 \%$ fetal bovine serum, $1 \%$ non-essential amino acids, $1 \%$ L-glutamine, penicillin $100 \mathrm{IU} / \mathrm{ml}$, and streptomycin $100 \mu \mathrm{g} / \mathrm{ml}$ in an atmosphere of $10 \% \mathrm{CO}_{2}$ and $90 \%$ air. ${ }^{1415}$ The medium was changed every 48 hours and cells were passaged every seven days in a split ratio of $1: 4$. For experiments, cells were seeded into 9.6 $\mathrm{cm}^{2}$, six-well, tissue culture treated polystyrene plates (Becton Dickinson, UK) in a split ratio of $1: 18$, and the medium was replaced every 48 hours. Cells reached confluency within three to five days. Cells between passage 92-102 were used. The number of Caco- 2 cells per well was estimated by counting cells with an inverted microscope using a grid lens with a field diameter of $0.9 \mathrm{~mm}$ and multiplying the cell count obtained by the number of fields per well. The median number of cells 16 days after passage was $2 \cdot 0 \times 10^{6}$ cells/well $(n=10)$.

\section{DIFFERENTIATION OF CACO-2 CELLS}

Functional differentiation of Caco-2 cells was determined by assay of sucrase and maltase activity after a varying duration of culture. For this, cell monolayers were washed twice with chilled $0.15 \mathrm{M}$ phosphate buffered saline (PBS), then harvested in $1 \mathrm{ml}$ ice cold distilled water. Cells were gently homogenised to a fine suspension by rapid pipetting, and disaccharidase activity was determined using modifications of the glucose oxidase-peroxidase method. ${ }^{20}{ }^{21}$ Briefly, $10 \mu$ l duplicate aliquots of appropriately diluted, homogenised Caco-2 samples were incubated with $0.056 \mathrm{M}$ disaccharide substrate in $0 \cdot 1 \mathrm{M}$ phosphate buffer solution in 96 well microtitre plates (Becton Dickinson, UK) at $37^{\circ} \mathrm{C}$ for one hour. TRISglucose oxidase reagent $(250 \mu \mathrm{l})$ was added and plates were incubated for a further hour. A substrate blank was included for each sample. Plates were read on a Titertek Multiscan microplate reader (Flow Laboratories, UK) at $510 \mathrm{~nm}$ and the enzyme activity was expressed as $U / \mu$ g protein. Protein was estimated with the bicinchoninic acid protein assay reagent method $^{22}$ (BCA, Pierce, USA).

The structural differentiation of Caco- 2 cells was assessed 16 days after passage by scanning electron microscopy. Cells grown on tissue culture-treated, $10 \mathrm{~mm}$ round, glass cover slips were double fixed in $3 \%$ glutaraldehyde in $0 \cdot 1$ $\mathrm{M}$ phosphate buffer at $\mathrm{pH} 7 \cdot 4$ followed by $1 \%$ aqueous osmium tetroxide. They were dehydrated, critically point dried using $\mathrm{CO}_{2}$, sputter coated with gold palladium, and examined in a JEOL SEM 5300. Electron micrographs were kindly taken by $\mathrm{Dr}$ Alan Phillips, Electron Microscopy Department, Queen Elizabeth Hospital for Sick Children, London.
GIARDIA-CACO-2 CELL CO-INCUBATION

To determine the optimal medium for coincubation, preliminary attachment assays were done (as described below) with four different media: supplemented DMEM, modified TYI-S-33, modified RPMI-1640, and modified $\mathrm{HSP}_{3}\left(\mathrm{MHSP}_{3}\right)$. The latter two media have been reported to support growth of both giardia and mammalian cells. ${ }^{12} 23$ Co-incubation was in a ratio of giardia:Caco-2 cells of $1: 10$, at $37^{\circ} \mathrm{C}$ in $5 \% \mathrm{CO}_{2}, 95 \%$ air for one hour. Giardia motility 24 hours after coincubation in these media was assessed qualitatively. Giardia attachment was: 24 (5)\% in supplemented DMEM, 27 (4)\% in modified TYI-S-33, 13 (3)\% in modified RPMI-1640 and $42(4) \%$ in $\mathrm{MHSP}_{3}, \quad(\mathrm{n}=6$ for each medium). On the basis of these results, $\mathrm{MHSP}_{3}$ was selected for use in experiments, as attachment was maximal $(p<0 \cdot 02)$, giardia motility was preserved and it provided the best compromise between the metabolic needs of the micro-organism and the mammalian cell.

\section{CO-INCUBATION AND ATTACHMENT ASSAY}

Giardia were decanted and the remaining attached trophozoites were re-fed with modified $\mathrm{MHSP}_{3}$ media and chilled on ice until detached. Trophozoites were then centrifuged at $1000 \times g$ for 10 minutes, the supernatant was decanted, and the pellet resuspended in $\mathrm{MHSP}_{3}$ medium warmed to $37^{\circ} \mathrm{C}$. An aliquot was counted using a haemocytometer and the volume was adjusted to give the desired concentration of trophozoites per ml. Giardia were then co-incubated with Caco-2 cells using modifications of a method previously described. ${ }^{12}$ Medium was aspirated from Caco-2 cells and the monolayers gently washed with warmed $\mathrm{MHSP}_{3}$ medium to remove any cells that had not adhered or debris. Giardia were then added and the volume adjusted to 3 $\mathrm{ml}$ per well. Plates were incubated at $37^{\circ} \mathrm{C}$ in $5 \% \mathrm{CO}_{2}$ and $95 \%$ air. The percentage attachment of giardia to Caco-2 cell monolayers was estimated by determining the ratio of attached: total giardia seeded. At the end of the incubation period unattached trophozoites were recovered by gently rinsing culture plates three times with $\mathrm{MHSP}_{3}$ medium warmed to $37^{\circ} \mathrm{C}$. Adherent trophozoites were then recovered by repeated washes with ice cold $\mathrm{Ca}^{2+}$ and $\mathrm{Mg}^{2+}$ free $0 \cdot 15$ M PBS (Dulbecco's formula, Flow Laboratories, UK) over 15-20 minutes until no trophozoites were visible when checked by light microscopy. An aliquot from each of these samples was counted in a haemocytometer and attachment was expressed as the percentage attached of the total number recovered.

The time course of attachment was determined over 24 hours and the effect of varying the number of giardia was studied over a range of giardia:Caco-2 cell ratios from 1:100 to 1:2. The impact of physicochemical factors on attachment was studied by varying the incubation temperature $\left(4^{\circ}, 21^{\circ}, 37^{\circ} \mathrm{C}\right)$ and by adjusting the $\mathrm{pH}$ of the medium with $\mathrm{HCl}$ or $\mathrm{NaOH}$ over a $\mathrm{pH}$ range of $5 \cdot 5-9 \cdot 2$. The 


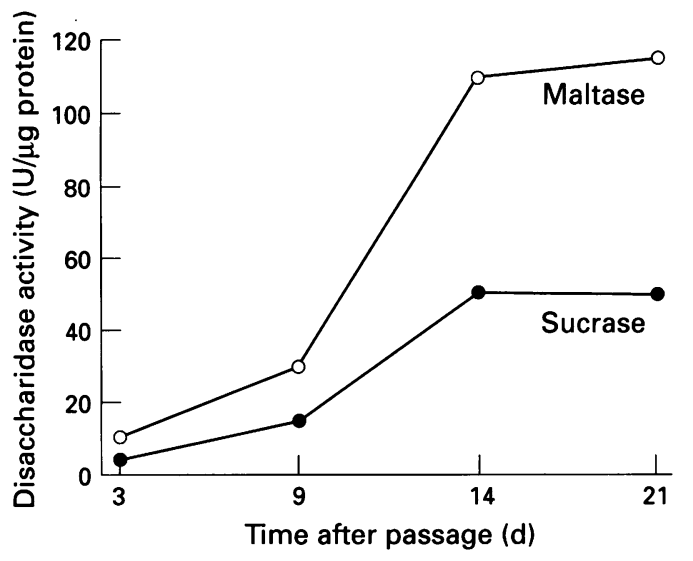

Figure 1: The time course for the expression of disaccharidase activity in Caco-2 cells ( $n=6$ for each point).

divalent cation dependency of attachment was determined by co-incubating giardia in the presence of EDTA $2.5 \mathrm{mM}$. These experiments and those following, unless otherwise stated, were done with isolate WB, on Caco-2 cells 15-17 days after passage in 5\% $\mathrm{CO}_{2}$ and $95 \%$ air. The percentage attachment was compared between three different giardia isolates and a clone. As bile promotes growth of trophozoites in vitro, ${ }^{18} 24$ an effect on attachment was sought by comparing attachment of trophozoites passaged in the presence and absence of bovine bile in the culture medium.

To determine the role of components of the giardia cytoskeleton in attachment, assays were done in the presence of microtubule inhibitors colchicine (dissolved in PBS) and mebendazole $(1 \cdot 0-100 \mu \mathrm{g} / \mathrm{ml}$, Sigma Chemical Co, St Louis, USA) and after 15 minutes' preincubation of trophozoites with the microfilament inhibitor, cytochalasin B (dissolved in DMSO $1 \%$ ). The role of giardia lectin in attachment was studied by preincubating giardia for 15 minutes with $\mathrm{D}$-mannose (5-100 $\mathrm{mM})$, mannose-6-phosphate $(3 \cdot 5-70$ $\mathrm{mM}$ ), and D-glucose (5-300 $\mathrm{mM})$. Glucose studies were done using PBS for co-incubation. Attachment was also determined after giardia had been pre-incubated in trypsin $(0.01-10.0 \mathrm{mg} / \mathrm{ml})$ for 20 minutes (Sigma type XIII) to determine whether previously reported lectin activation by trypsin in giardia sonicate is also evident in whole trophozoites. ${ }^{25}$ Further studies were done pre-incubating Caco-2 cells for 15 minutes with concanavalin A (10-100 $\mu \mathrm{g} / \mathrm{ml})$, which binds mannosyl residues.

\section{CONTROLS}

For all experiments, the results were compared with an equal number of control attachment assays. These assays were done at the same time as test wells, under identical conditions but without the alteration of co-culture parameter on the compound being tested. Where possible controls were included in the same culture plates as test wells. Further control experiments were done in medium containing DMSO $1 \%$.

\section{SCANNING ELECTRON MICROSCOPY}

Scanning electron micrographs of giardia after co-incubation with Caco-2 cells for one hour and 16 hours were obtained, using the methods described above.

\section{STATISTICAL ANALYSIS}

Results are expressed as mean (SEM). Differences between means were compared using two-tailed Student's $t$ tests or analysis of variance where appropriate. All data represent a minimum of $n=6$ for each data point and experiments were carried out on at least three separate occasions.

\section{Results}

CACO- 2 CELLS MODEL

The time course for the expression of disaccharidase activity is shown in Figure 1. Enzyme activity rose sharply from day 9 after passage and reached a plateau after day 14, indicating functional differentiation. ${ }^{17}$ The presence of confluent monolayers with microvilli on the apical surface of cells provided evidence of structural differentiation. As has been previously observed, ${ }^{15} 17$ the density of the microvilli varied between cells indicating the heterogeneity of the cell population. Some cells showed dense microvilli, others had clusters, while a few cells had sparsely present microvilli (Fig 2). On the basis of these findings, cells 15-17 days after passage were used for attachment experiments as functional and structural differentiation was evident.

At the end of the co-incubation period, Caco-2 cell monolayers remained confluent and appeared intact with normal morphology when examined by light microscopy and scanning electron microscopy. Giardia remained viable after co-incubation as trophozoites were motile and could be successfully subcultured after recovery from culture wells.

PHYSICOCHEMICAL FACTORS IN ATTACHMENT Using an inoculum of $2.0 \times 10^{5}$ trophozoites at $37^{\circ} \mathrm{C}$ and $\mathrm{pH} 7 \cdot 2$, giardia attachment to Caco2 cells increased with time up to 60 minutes, then reached a plateau. The range of attachment over one to eight hours was 40-46 (6)\% of the total number added. Attachment was still evident by 24 hours. The time course of attachment is shown in Figure 3. The total number of organisms recovered was between $75-115 \%$ of the estimated inoculum added for time periods up to eight hours. After 24 hours co-incubation, giardia numbers had increased to $5.1 \times 10^{5}$ indicating multiplication of trophozoites (generation time $=17$ hours). Multiplication was not evident after shorter periods of co-incubation. Attachment was temperature dependent, being maximal at $37^{\circ} \mathrm{C}\left(43.5(4) \%\right.$, reduced by $59 \%$ at $21^{\circ} \mathrm{C}$ $(17 \cdot 8(3) \%)$ and virtually abolished at $4^{\circ} \mathrm{C}(0.3$ $(0 \cdot 3) \%)$. Attachment occurred over a range of $\mathrm{pH}$ but was maximal at $\mathrm{pH} 7 \cdot 2-8 \cdot 2$ (Fig 4). The total number of trophozoites attached 

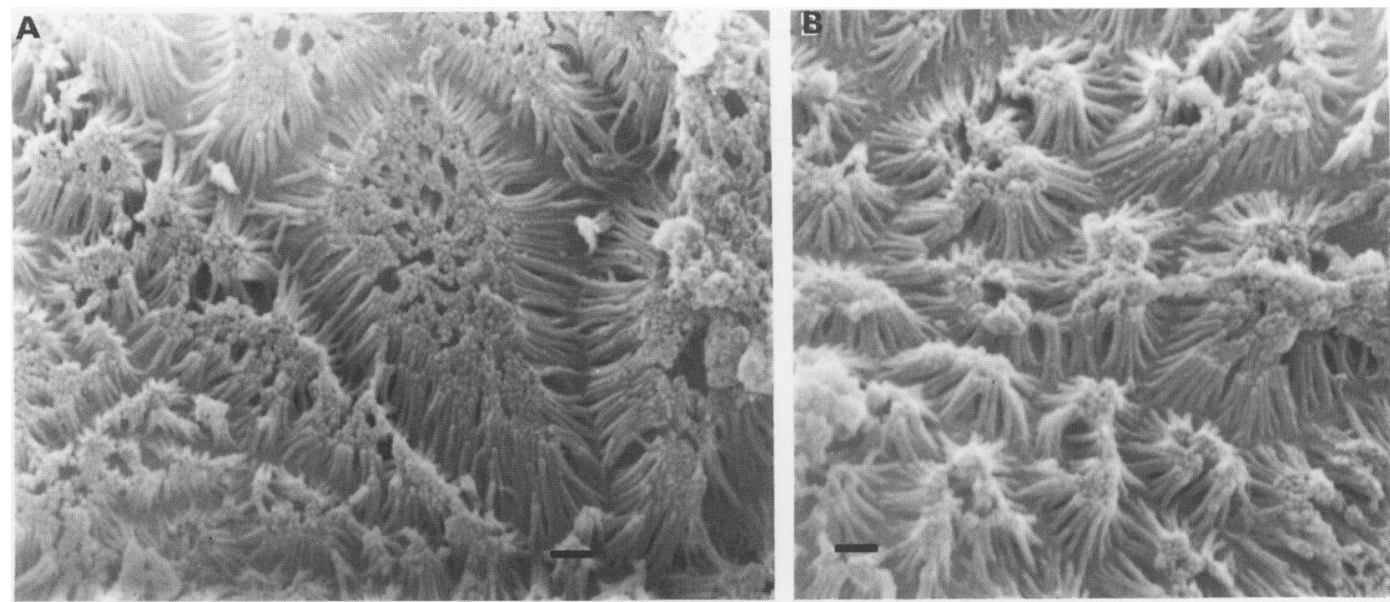

Figure 2: Scanning electron micrographs of Caco-2 cell monolayers 16 days after passage. (A) Structural differentiation is evidenced by the presence of microvilli on the apical surface of the cells. These cells have a dense array of microvilli. (Magnification $\times 7500 ;$ bar $=1 \mu \mathrm{m}$.) (B) These cells display clusters of microvilli on the apical surface. (Magnification $\times 7500 ;$ bar $=1 \mu \mathrm{m}$.)

after 60 minutes at $\mathrm{pH} 7 \cdot 2$ and $37^{\circ} \mathrm{C}$ increased with increasing numbers of giardia seeded, whereas the percentage attached was similar at all giardia:Caco-2 cell ratios (Fig 5). The foregoing experiments established the optimal conditions for the attachment assay. Unless otherwise stated, the results following were derived using a parasite:Caco-2 cell ratio of $1: 10$, over 60 minutes at $37^{\circ} \mathrm{C}, \mathrm{pH} 7 \cdot 2$, in $5 \%$ $\mathrm{CO}_{2}$ and $95 \%$ air.

CYTOSKELETAL INHIBITION AND CHELATION OF DIVALENT CATIONS

Chelation of divalent cations with EDTA $2 \cdot 5$ $\mathrm{mM}$ reduced attachment by $32(4) \%$ compared with controls $(p<0 \cdot 04)$. Higher concentrations of EDTA ( $\geqslant 5 \mathrm{mM}$ ) resulted in vacuolation and disruption of the Caco-2 cell monolayer. Co-incubation of giardia in the presence of colchicine or mebendazole resulted in a concentration dependent reduction in attachment compared with controls (Fig 6). Preincubation of giardia with cytochalasin B also significantly inhibited attachment compared to controls. This did not seem to be concentration dependent as the degree of inhibition of attachment was similar with $1 \mu \mathrm{g} / \mathrm{ml}$ and $20 \mu \mathrm{g} / \mathrm{ml}$ of cytochalasin B. A second control, using medium containing $1 \%$ DMSO (the solvent for the cytochalasin B)

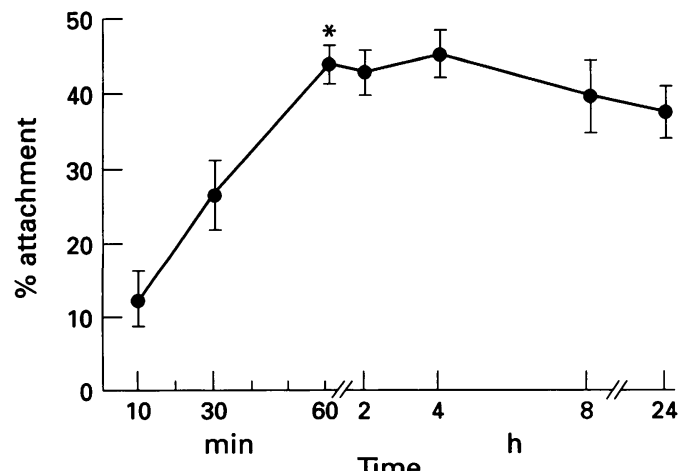

Figure 3: Time course of attachment of Giardia lamblia to Caco-2 cell monolayers under standard assay conditions ( $n \geqslant 6$ for each point; ${ }^{\star} p<0.01$ from 60 minutes compared with 10 minutes and 30 minutes). had no detrimental effect on attachment (Fig 6).

\section{LECTIN STUDIES}

Preincubation of trophozoites with D-mannose (5-100 $\mathrm{mM}$ ) reduced attachment by between 28 (4) and $35(5) \%(p<0.03)$. Preincubation with mannose-6-phosphate (35-70 $\mathrm{mM}$ ) reduced attachment by between 17 (5) and 24 $(5) \%(p<0.04)$. A lower concentration of mannose-6-phosphate $(3.5 \mathrm{mM})$ did not reduce attachment. With D-glucose, attachment was significantly reduced only at high concentration (300 mM, p <0.02), where diminished attachment is likely to be a result of raised osmolarity. Preincubation of Caco-2 cell monolayers with concanavalin A, 10 and 100 $\mu \mathrm{g} / \mathrm{ml}$ reduced giardia attachment by 11 (3)\% $(\mathrm{p}=\mathrm{NS})$ and $19(2) \%(\mathrm{p}<0.02)$, respectively.

\section{INFLUENCE OF HOST FACTORS}

Preincubating trophozoites for 20 minutes in medium containing trypsin $(0.01-10.0 \mathrm{mg} / \mathrm{ml})$ did not enhance subsequent attachment. On the contrary, attachment was reduced by $9-13$ (5)\% compared with controls. Attachment of

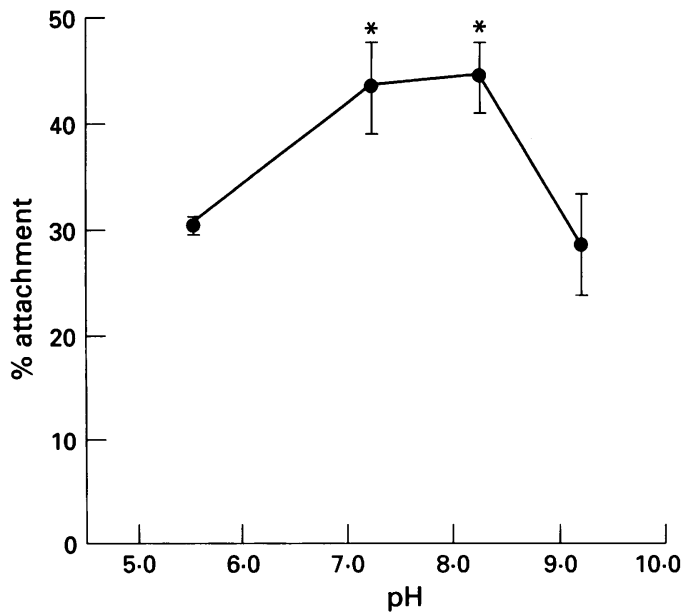

Figure 4: The $\mathrm{pH}$ dependency of attachment of Giardia lamblia under standard assay conditions, $\left({ }^{\star} p<0.02\right.$ compared with $p H 5 \cdot 5$ and $p H$ 9.2). 


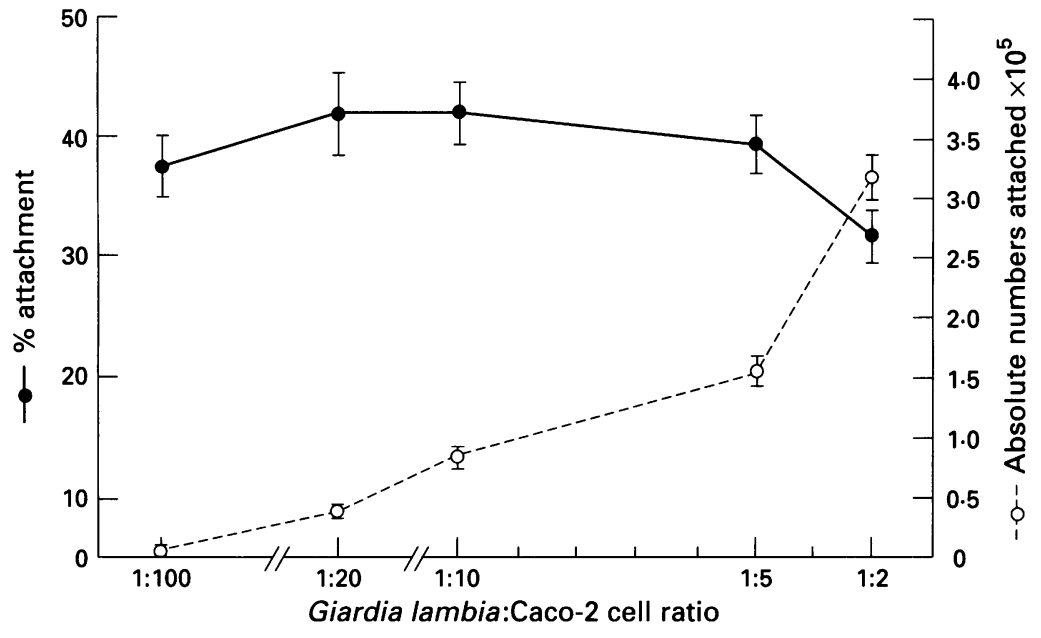

Figure 5: The relationship between Giardia lamblia:Caco-2 cell ratio and the percentage and absolute numbers of trophozoites attached ( $n=6-12$ for each point).

giardia was not different between isolates that had been grown in the presence (43 (3)\%) or absence of bile ( $45(3) \%, p=N S$ ).

\section{ISOLATE VARIATION}

The proportion of trophozoites attached did not vary significantly between three different isolates. Using the standard assay conditions, attachment was: WB 46 (4)\%, RW6 42 (3)\%, and VNB3 47 (5)\%. The clone of isolate WB attached to the same degree as the parent isolate (44 (5)\%).

\section{SCANNING ELECTRON MICROSCOPY}

Giardia were seen in close apposition and apparently attached to Caco- 2 cells. While most trophozoites were observed with their

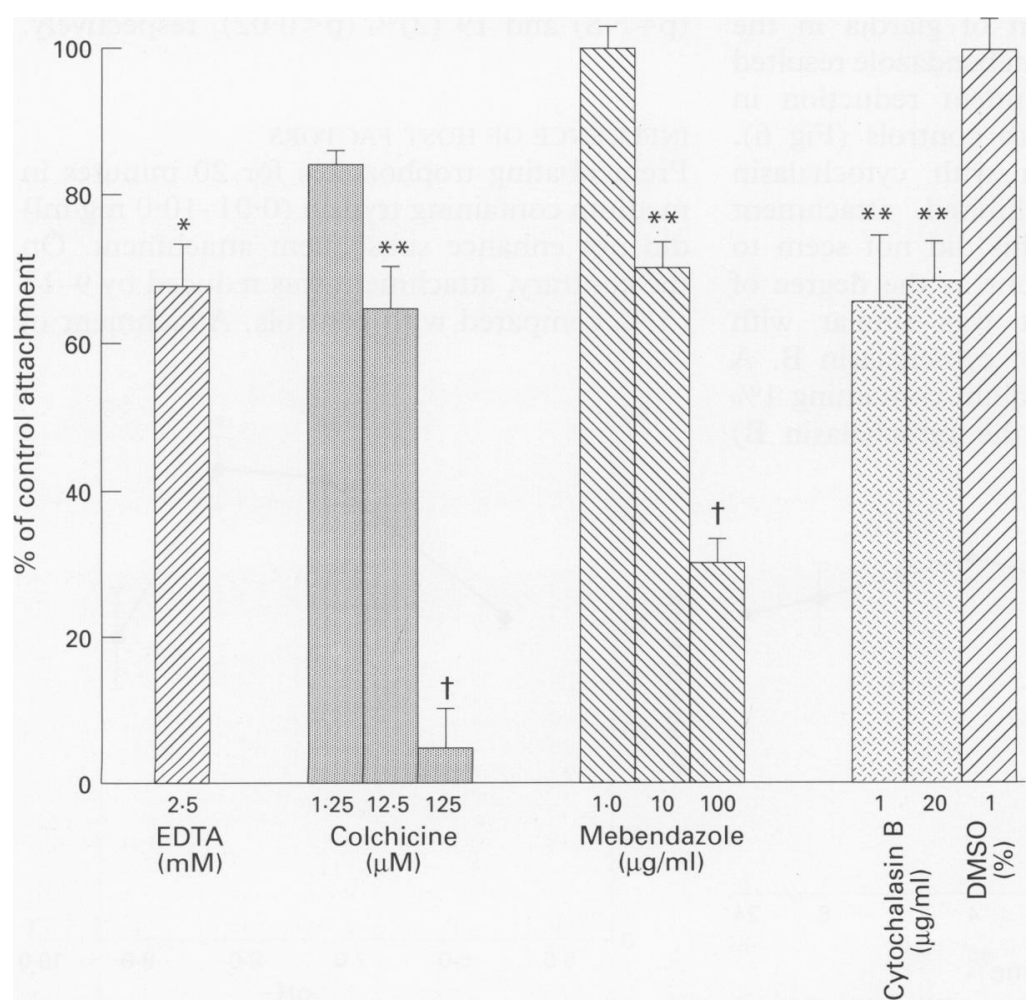

Figure 6: The effect of EDTA, colchicine, mebendazole, cytochalasin B and dimercaptosuccinic acid (DMSO) $1 \%$ on attachment of Giardia lamblia ( $n \geqslant 8$ for each point; ${ }^{\star} p<0.04,{ }^{\star \star} p<0.02,+p<0.001$ compared with controls). ventral surfaces applied to the monolayer, trophozoites were also seen with their dorsal surfaces opposed to Caco-2 cells, apparently bound by means other than the ventral sucker disc (Fig 7). Trophozoites did not seem to show a predilection for Caco- 2 cells with more dense microvilli.

\section{Discussion}

These experiments confirm giardia trophozoite attachment to differentiated Caco-2 cells in vitro and support a role for both cytoskeletal and lectin mediated mechanisms. This Caco-2 cell model is an appropriate model of attachment as it involves human isolates of giardia on a human enterocyte-like cell line. The assay is simple and reproducible. This is a more physiological model of attachment than those used in previous studies, where synthetic surfaces such as plastic or glass have been used. ${ }^{9}{ }^{10}$ These models are useful but have the obvious limitation that they are not biological. In other studies, animal cells were used. Human giardia isolates co-incubated with isolated rat enterocytes have been used to study attachment, particularly the role of giardia surface membrane lectin. ${ }^{8}$ This system has the disadvantage that adherence of trophozoites occurs to both the apical and basolateral surfaces of enterocytes, a situation that does not occur in vivo. Another model of attachment using radiolabelled human giardia and IEC- 6 cells, a cultured rat enterocyte line, has also been described. ${ }^{11}$

This study supports a primary role for mechanical attachment via the ventral disc with a prominent role for microtubules and contractile microfilaments. Attachment was inhibited by divalent cation depletion and cytochalasin B, which suggests interference with the actin-myosin system. Attachment was also reduced with colchicine and mebendazole, which affect microtubular function. ${ }^{26}$ Some previous reports have differed from these findings. In view of the different models and experimental procedures used to study attachment it is not surprising that experimental results have not always been concordant. Both Inge et $a l^{8}$ and Magne et $a l^{27}$ described decreased attachment of giardia to cells after microtubular inhibition, and of a similar magnitude to that found in the current study. However, Feely and Erlandsen ${ }^{9}$ did not find that colchicine inhibited attachment of giardia to plastic: Similarly, McCabe et al, ${ }^{11}$ using a physiological surface, also failed to find an effect, probably because the concentration of colchicine used $(1 \mu \mathrm{g} / \mathrm{ml})$ was too low. Inge et $a l^{8}$ did not show that divalent cation depletion or cytochalasin B affected attachment, perhaps because in that model, in which isolated rat enterocytes were used, lectin mediated attachment to basolateral as well as apical surfaces of enterocytes was marked. Gillin and Reiner ${ }^{10}$ found little effect of cytochalasins on adherence of trophozoites to glass but it is unclear whether other mechanical forces are involved in attachment to this surface. Curiously, Magne et $a l^{27}$ who used 

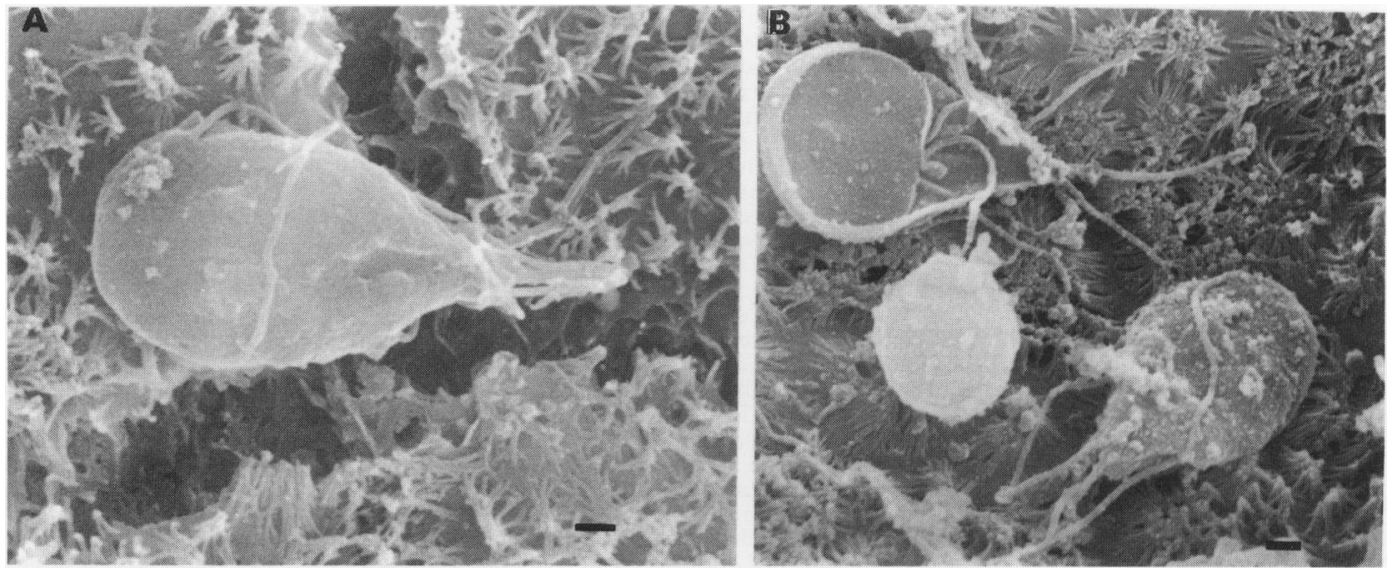

Figure 7: Scanning electron micrographs of Giardia lamblia coincubated with Caco-2 cells. (A) G lamblia trophozoite in close apposition and apparently attached to a Caco-2 cell. The ventral surface of the trophozoite is applied to the monolayer, which displays sparse microvilli (1 h co-incubation). (Magnification $\times 5000 ;$ bar $=1 \mu m$.) (B) $\mathrm{G}$ lamblia trophozoites in dorsal and ventral orientation to Caco-2 cells (16 h co-incubation). (Magnification $\times 5000 ;$ bar $=1 \mu \mathrm{m}$.)

Caco-2 cells as a model for attachment, reported a biphasic increase of attachment to Caco-2 cells after inhibition of contractile proteins with cytochalasin $\mathrm{B}$, a finding which is at odds with other previous studies and the current work and may be the result of a low number of repeat experiments. This also conflicts with a previous report from the same group using this model, which described reduced attachment to Caco-2 cells after inhibition of contractile proteins by chelation of divalent cations. ${ }^{12}$ The current study shows the importance of both divalent cation depletion with EDTA and microfilament inhibition with cytochalasin B in reducing attachment of giardia to a human cell line. This is consistent with data from models using plastic surfaces and cell lines that are not human ${ }^{911}$ and supports the role of contractile filaments in attachment.

Lectin mediated attachment was evident in this system, inhibitable by D-mannose, mannose-6-phosphate, and concanavalin A, consistent with a mannosyl target for binding. No enhancement of attachment was seen after exposure to trypsin which suggests that the trypsin activation of giardia lectin described in giardia sonicate ${ }^{2528}$ does not have biological importance for attachment. Evidence suggests that lectin mediated binding is not the primary mode of attachment of giardia. Firstly, attachment to synthetic surfaces is avid and is not dependent on receptor-ligand mediated binding. Secondly, the magnitude of the reduction in attachment is greater after inhibition of cytoskeletal function than with competitive inhibitin of lectin mediated binding. Lastly, although giardia are found in various orientations to epithelial cells, most trophozoites are observed ventral surface down. Avidity for binding of giardia to rat intestinal cells has been shown to be greater with more proximal intestinal cells. ${ }^{8}$ It is possible that lectin mediated attachment serves to localise giardia to its preferred intestinal site and that trophozoites subsequently reorientate and attach via the ventral disc.

This model allows physiological manipulation of the co-culture medium to mimic some conditions in the small intestine. For example, pancreatic bicarbonate secretion into the duodenum results in periodically elevated luminal $\mathrm{pH}$ and giardia survive in this alkalinised milieu. It is not known whether this is because giardia can resist a raised $\mathrm{pH}$ or because trophozoites may avoid exposure to luminal contents by burrowing under the mucus layer. With this model, attachment has been demonstrated to be maintained despite direct exposure to alkaline conditions up to a $\mathrm{pH}$ of $8 \cdot 2$.

In summary, the giardia-Caco-2 cell coincubation model seems to be a relatively simple and useful vehicle for the study of the attachment of giardia in vitro. A predominant role for mechanical attachment via cytoskeletal mechanisms is suggested by these studies, although lectin associated binding is present and may also have a role in vivo.

This study was supported by the Wellcome Trust, London. Part of this work was presented at the American Gastroenterological Association meeting in Boston 1993 (Gastroenterology 1993, 104: A721).

1 Erlandsen SL. Scanning electron microscopy of intestinal giardiasis: Lesions of the microvillous border of the villus epithelial cells produced by trophozoites of Giardia pp. 775-82. In: Johari O, ed Scanning electron microscopy. Chicago: IIT Research Institute, 1974.

2 Smith PD. Pathophysiology and immunology of giardiasis. Ann Rev Med 1985; 36: 295-307.

3 Holberton DV. Arrangement of subunits in microribbons from Giardia. $\mathcal{F}$ Cell Sci $1981 ; 47$ : 167-85.

4 Peattie DA, Alonso RA, Hein A, Caulfield JP Ultrastructural localisation of giardins to the edges of disk microribbons of Giardia lamblia and the nucleotide and deduced protein sequence of alpha giardin. $\mathcal{F}$ Cell Biol 1989; 109: 2323-35.

5 Feely DE, Schollmeyer JV, Erlandsen SL. Giardia: distribution of contractile proteins in the attachment organelle. Exp Parasitol 1982; 53: 145-54.

6 Holberton DV. Attachment of Giardia - a hydrodynamic model based on flagellar activity. f Exp Biol 1974; 60: 207-21

7 Farthing MJG, Periera MEA, Keusch GT. Description and characterization of a surface lectin from Giardia lamblia. Infect Immun 1986; 51: 661-7.

8 Inge PMG, Edson CM, Farthing MJG. Attachment of Giardia lamblia to rat intestinal epithelial cells. Gut 1988 ; 29: 795-801.

9 Feely DE, Erlandsen SL. Effect of cytochalasin-B, low $\mathrm{Ca}^{++}$concentration, iodoacetic acid and quinacrine-HCl on the attachment of Giardia trophozoites in vitro. 7 Parasitol 1982; 68: 869-73.

10 Gillin FD, Reiner DS. Attachment of the flagellate Giardia lamblia: role of reducing agents, serum, temperature, and ionic composition. Mol Cell Biol 1982; 2: 369-77.

1 McCabe RE, Yu GSM, Conteas C, Morrill PR, McMorrow B. In vitro model of attachment of Giardia intestinalis trophozoites to IEC-6 cells, an intestinal cell line. Antimicrob Agents Chemother 1991; 35: 29-35.

12 Favennec L, Chochillon C, Meillet D, Magne D, Savel J, Raichvarg $\mathrm{D}$, et al. Adherence and multiplication of 
Giardia intestinalis on human enterocyte-like differentiated cells in vitro. Parasitol Res 1990; 76: 581-4

13 Pinto $M$, Robine-Leon S, Appay $M D$, Kerdinger $M$, Triadou N, Dussaulx E, et al. Enterocyte-like differentiation and polarisation of the human colon carcinoma cell line Caco-2 culture. Biol Cell 1983; 47: 323-30.

14 Hidalgo IJ, Raub TJ, Borchardt RT. Characterisation of the human colon carcinoma cell line (Caco-2) as a model system for intestinal epithelial permeability. Gastroenterology 1989; 96: 736-49.

15 Wilson G, Hassan IF, Dix CJ, Williamson I, Shah R, Macka $M$, Transport and permeability properties of huma Caco-2 cells: an in vitro model of the intestinal epithelial cell barrier. Fournal of Controlled Release 1990; 11: 25-40.

16 Matsumoto H, Erickson RH, Gum JR, Yoshioka M, Gum E, Kim YS. Biosynthesis of alkaline phosphatase during differentiation of the human colon cancer cell line Caco-2 Gastroenterology 1990; 98: 1199-207.

17 Vachon PH, Beaulieu J-F. Transient mosaic patterns of morphological and functional differentiation in the Caco2 cell line. Gastroenterology 1992; 103: 414-23.

18 Keister DB. Axenic culture of Giardia lamblia in TYI-S-33 media supplemented with bile. Trans Roy Soc Trop Med Hyg 1983; 77: 487-8.

19 Baum KF, Berens RL, Jones RH, Marr J. A new method for cloning Giardia lamblia, with a discussion of the statistical considerations of limiting dilution. 7 Parasitol 1988; 74: 267-9.

20 Belosevic M, Faubert GM, MacLean JD. Disaccharidase activity in the small intestine of gerbils (Meriones unguiculatus) during primary and challenge infections with Giardia lamblia. Gut 1989; 30: 1213-9.

21 Dahlqvist A Assay of intestinal disaccharidases. Anal Biochem 1968; 22: 99-107.

22 Smith PK, Krohn RI, Hermanson GT, Mallai AK, Gartner FH, Provenzano MD, et al. Measurement of protein using bicinchoninic acid. Anal Biochem 1985; 150: 76-85.

23 Guy RA, Bertrand S, Faubert GM. Modification of RPMI1640 for use in in vitro immunological studies of hostparasite interactions in giardiasis. $\mathcal{F}$ Clin Microbiol 1991; 29: 627-9.

24 Farthing MJG, Varon SR, Keusch GT. Mammalian bile promotes growth of Giardia lamblia in axenic culture. Trans Roy Soc Trop Med Hyg 1983; 77: 467-9.

25 Lev B, Ward H, Keusch GT, Pereira MEA. Lectin activation in Giardia lamblia by host protease: A novel hostparasite interaction. Science 1986; 232: 71-3.

26 Edlind TD anthelmintic benzimidazoles against Giardia lamblia in vitro. F Infect Dis 1990; 162: 1408-11.

27 Mane Dennec $\mathrm{D}, \mathrm{Kapel} \mathrm{N}$, et al. Role of cytoskeleton and surface lectins in Giardia duodenalis attachment to $\mathrm{Caco} 2$ cells. Parasitol Res 1991; 77: 659-62.

28 Ward HD, Lev BI, Kane AV, Keusch GT, Pereira ME. Identification and characterization of taglin, a mannose 6 phosphate binding, trypsin-activated lectin from Giardia lamblia. Biochemistry 1987; 26: 8669-75. 